\title{
HOMOGENEOUS ENZYME-LINKED COMPETITIVE BINDING ASSAY FOR RIBOFLAVIN
}

\author{
GEUN SIG CHA and MARK E. MEYERHOFF* \\ Department of Chemistry, University of Michigan, Ann Arbor, MI 48109 (U.S.A.)
}

(Received 19th October 1987)

\section{SUMMARY}

A rapid and precise homogeneous enzyme-linked competitive binding assay for riboflavin (vi$\operatorname{tamin} B_{2}$ ) is described. The method utilizes a malate dehydrogenase/3-carboxymethylriboflavin conjugate in conjunction with soluble riboflavin binding protein. In the absence of the vitamin, the catalytic activity of the enzyme/riboflavin conjugate is inhibited up to $71 \%$ by the binding protein. In the presence of riboflavin, activity is regained in an amount dependent on the riboflavin concentration. The detection limits of the dose/response curves are dependent on both the degree of conjugation (average number of 3-carboxymethylriboflavins per enzyme molecule) and the reagent ratio (conjugate/binder) used in the assay tube. Under optimized conditions, a detection limit of $3 \mathrm{ng} \mathrm{ml}^{-1}$ of riboflavin can be achieved with high selectivity over other vitamins and biomolecules. While malate dehedrogenase activity is inhibited to some degree by components of human urine, use of riboflavin standards prepared in a diluted urine matrix enables the method to be utilized for direct determination of urinary riboflavin.

Enzyme-linked competitive-binding assays are now used routinely in place of radioimmunoassay methods to detect a wide variety of biomolecules at trace levels [1-4]. Such methods may be classified as either heterogeneous or homogeneous. The homogeneous types do not require time-consuming separation of free and bound enzyme label. Indeed, analytical signals result from either activation or inhibition of enzyme-conjugate catalytic activity in solution by antibody (or binding protein) interactions with the conjugate. Thus, homogeneous assays are simple, fast, and easily automated.

A solid-phase enzyme-linked riboflavin assay was developed recently by utilizing a glucose-6-phosphate dehydrogenase/riboflavin conjugate in conjunction with immobilized riboflavin-binding protein (RBP) (in place of antibody) [5]. The method was shown to be quite selective and sensitive; a detection limit of $0.7 \mathrm{pmol}$ per assay tube was achieved. However, like other heterogeneous methods, the method required rather long incubation periods and tedious separation steps.

In this paper, the use of RBP as a reagent in enzyme-linked competitivebinding assays is further extended by describing a very rapid and precise homogeneous method for the determination of riboflavin. The method utilizes a 
malate dehydrogenase/3-carboxymethylriboflavin conjugate in conjunction with soluble RBP. Malate dehydrogenase (MDH) conjugates prepared in this study can be inhibited up to $71 \%$ in the presence of soluble RBP. These same conjugates possess high specific activities and low degrees of ligand substitution which enable the resulting assays to be rather sensitive. The detection limits of the dose-response curves are dependent on both the degree of ligand substitution and the reagent ratio used in the assay tube. Under optimized conditions, this new method is shown to offer adequate detection limits and selectivity for use in the direct determination of riboflavin in multivitamin preparations and human urine.

\section{EXPERIMENTAL}

\section{Apparatus}

Enzyme activities were measured with a Gilford Stasar-III spectrophotometer equipped with a vacuum-operated sampling system and temperaturecontrolled cuvette (maintained at $30^{\circ} \mathrm{C}$ throughout the experiments). The spectrophotometer was connected to a Syva CP-5000 EMIT clinical processor for automatically setting the reading intervals and recording the absorbance values. A Syva pipetter/diluter (Model 1500) was used for delivering the conjugate, binder, and substrate solutions. A Perkin-Elmer Lambda Array 3840 photodiode array ultraviolet/visible spectrophotometer operated by a Model 7300 Professional computer was used to record the absorption spectra of the enzyme, riboflavin, riboflavin analogs, and conjugates.

\section{Reagents}

Malate dehydrogenase (MDH) from porcine heart mitochondrial, NADH, oxaloacetic acid, apo-riboflavin binding protein (RBP) from chicken egg white, riboflavin, lumiflavin, lumichrome, flavin mononucleotide (FMN), flavin adenine dinucleotide (FAD), as well as all other biochemicals were obtained from Sigma Chemical Co. and were of the highest purity available. Deionized water was used throughout the study.

Activity measurements of $\mathrm{MDH}$ and its conjugates were made in a $0.10 \mathrm{M}$ sodium phosphate buffer, $\mathrm{pH} 7.5$, containing $0.01 \%(\mathrm{w} / \mathrm{v})$ sodium azide (assay buffer ). The dilutions of conjugates, binders, standards, and samples were made by using this assay buffer containing $0.10 \%(\mathrm{w} / \mathrm{v})$ gelatin and 2.0 or $5.0 \%$ $(\mathrm{w} / \mathrm{v})$ bovine serum albumin (Tris/gel/BSA buffer).

\section{Preparation of $M D H / 3$-carboxymethylriboflavin conjugates}

3-Carboxymethylriboflavin and its $N$-hydroxysuccinimide (NHS)-activated ester were synthesized by using the procedure described previously [5]. In order to prepare $\mathrm{MDH} / 3$-carboxymethylriboflavin conjugates, the required amount of NHS-activated 3-carboxymethylriboflavin (dissolved in dimethyl 
sulfoxide, $15 \mathrm{mg} / 200 \mu \mathrm{l})$ was added to an $800-\mu \mathrm{l}$ aliquot of the enzyme solution (1250 units $\mathrm{ml}^{-1}$, previously dialyzed against $0.10 \mathrm{M}$ sodium phosphate, $\mathrm{pH}$ 7.5 ) at $4^{\circ} \mathrm{C}$ with vigorous stirring. The conjugation reaction was run for $4 \mathrm{~h}$ in the dark at $4^{\circ} \mathrm{C}$ with stirring. The reaction mixture was then dialyzed against the assay buffer $(0.10 \mathrm{M}$ sodium phosphate $/ 0.01 \%$ sodium azide, $\mathrm{pH} 7.5)$.

Each conjugate was characterized by the degree of conjugation (average number of ligands per enzyme molecule), by its residual enzymatic activity, and by the percent inhibition induced by excess of RBP. The degree of conjugation was estimated from calculations involved absorbance measurements at two wavelengths (225 nm and $452 \mathrm{~nm}$ ) [6]. A molecular weight of 70000 was assumed for MDH [7]. The residual enzymatic activity was calculated by comparing the activity of a conjugated enzyme to that of a solution containing unconjugated enzyme of the same protein concentration.

\section{Procedures}

Determinations of enzymatic activity and maximum percent inhibition. The rate of decrease in NADH concentration, measured by the change in absorbance at $340 \mathrm{~nm}$ per unit time, was used to determine the activity of the $\mathrm{MDH} /$ riboflavin conjugates. To determine $\mathrm{MDH}$ activity, $400 \mu \mathrm{l}$ of a mixed $\mathrm{NADH}$ and oxaloacetic acid substrate solution $\left(6.4 \times 10^{-4} \mathrm{M} \mathrm{NADH}\right.$ and $1.9 \times 10^{-3} \mathrm{M}$ oxaloacetic acid in assay buffer) was added to a $1.8-\mathrm{ml}$ polypropylene tube (with cap) containing $200 \mu \mathrm{l}$ of the conjugate solution and $400 \mu \mathrm{l}$ of Tris/gel/BSA (2\%) buffer. Both the substrate solution and the dilution of the conjugate were freshly prepared prior to use and kept at $0^{\circ} \mathrm{C}$ until the addition. After mixing and agitation $(10 \mathrm{~s})$, the reaction mixture was aspirated into the thermostated flow cell of the spectrophotometer. After a 20 -s delay, absorption measurements were taken over a 1 -min period $\left(\triangle A \mathrm{~min}^{-1}\right)$.

In order to obtain data for maximum percent inhibition (Table 1) for each conjugate, $100 \mu \mathrm{l}$ of an RBP solution ( $1 \mathrm{mg} \mathrm{ml}^{-1}$ ) was substituted for $100 \mu \mathrm{l}$ of the Tris/gel/BSA buffer used above. In addition, a 10-min incubation interval preceded the addition of the substrate solution to the assay mixture.

Association kinetic study. An RBP solution $\left(400 \mu \mathrm{l}, 15.6 \mu \mathrm{g} \mathrm{ml}^{-1}\right)$ in Tris/gel/BSA buffer was incubated for varying periods of time with $200 \mu \mathrm{l}$ of $7.1 \times 10^{-9} \mathrm{M}$ conjugate (conj-14) in the same buffer. After each incubation period, $400 \mu \mathrm{l}$ of the substrate solution was added and the enzymatic activity was determined as described above.

Binding-protein dilution curves. Portions $(400 \mu \mathrm{l})$ of solutions containing different amounts of RBP were incubated with $200 \mu \mathrm{l}$ of $7.1 \times 10^{-9} \mathrm{M}$ conjugate (conj-12, conj-14, and conj-17) for $15 \mathrm{~min}$. The substrates were then added and the enzymatic activity was measured as above. A binder dilution curve was prepared by plotting percent inhibition vs. amount of RBP added.

Dose/response curves. Standard solutions of each flavin (riboflavin, lumiflavin, lumichrome, FMN, and FAD) were prepared as described previously 
TABLE 1

Parameters of $\mathrm{MDH} / 3$-carboxymethylriboflavin conjugates

\begin{tabular}{lclll}
\hline Conjugate & $\begin{array}{l}\text { Initial } \\
\text { ester/enzyme } \\
\text { ratio }\end{array}$ & $\begin{array}{l}\text { Degree of } \\
\text { conjugation }\end{array}$ & $\begin{array}{l}\text { Residual } \\
\text { activity } \\
(\%)\end{array}$ & $\begin{array}{l}\text { Inhibition } \\
(\%)\end{array}$ \\
\hline Conj-11 & 5 & 1.2 & 59.8 & 25.5 \\
Conj-12 & 10 & 2.0 & 49.7 & 44.7 \\
Conj-13 & 20 & 3.2 & 38.4 & 64.4 \\
Conj-14 & 30 & 4.4 & 33.7 & 69.7 \\
Conj-15 & 40 & 5.2 & 31.3 & 71.4 \\
Conj-16 & 50 & 6.6 & 29.1 & 71.2 \\
Conj-17 & 100 & 12.4 & 18.4 & 60.6 \\
Conj-18 & 250 & & Insoluble & \\
Conj-19 & 500 & & Insoluble & \\
\hline
\end{tabular}

${ }^{\text {a }}$ Refers to molar ratios of NHS-activated 3-carboxymethylriboflavin to MDH in the conjugation

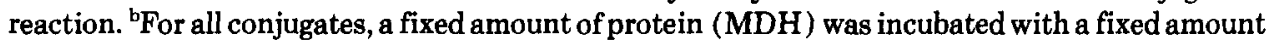
of RBP.

[5] except that Tris/gel/BSA buffer was used to dilute each stock solution. In the homogeneous assay protocol, $200 \mu \mathrm{l}$ of a standard solution and $200 \mu \mathrm{l}$ of a conjugate solution were sequentially added to an assay tube containing $200 \mu \mathrm{l}$ of an RBP solution and the mixture was incubated for $15 \mathrm{~min}$ at room temperature. The resulting enzymatic activity was measured as outlined above Dose/response curves were constructed by plotting percent inhibition or absorbance change $\Delta A \mathrm{~min}^{-1}$ at $340 \mathrm{~nm}$ vs. logarithm of the flavin concentration in the standards.

Determination of riboflavin in multivitamin preparations. The contents of 7-50 capsules or tablets of commercial multivitamin preparations were weighed, powdered, and mixed. A quantity of each powdered mixture (15-40 mg) was then weighed and dissolved in 21 of phosphate buffer. From this sample solution, further dilutions in Tris/gel/BSA (2\%) buffer were prepared and stored in the dark at $4^{\circ} \mathrm{C}$. These samples were processed (as soon as possible) according to the homogeneous assay protocol described above. The unknown concentrations were estimated graphically from the calibration curve. Only the steep portion of the dose/response curve was used for analytical purposes. The same samples were also assayed for riboflavin by a fluorescence titration method, following the procedure described by Tillotson and Bashor [8].

Urine analysis. Twenty-two random urine samples were collected and frozen in the dark until assayed. A riboflavin-free urine pool was prepared by incubating numerous urine samples with an excess quantity of high coverage RBP beads (RBP immobilized on Sepharose, prepared as described earlier [5]) to remove riboflavin. This urine pool was then diluted $1: 10,1: 20$, or $1: 40$ with Tris/gel/BSA (5\%) buffer and used for the preparation of the standard ribo- 
flavin solutions (urine-based standards). The unknown urine samples were diluted $1: 10,1: 20$, or $1: 40$ with the same buffer and analyzed according to the homogeneous assay protocol. For the urine assays, both the RBP and conjugate solutions were prepared with Tris/gel/BSA (5\%) buffer. The amount of urinary riboflavin in the unknown samples was graphically determined from the corresponding calibration curve (i.e., standard solutions prepared with a urine pool diluted as much as the urine samples).

\section{RESULTS AND DISCUSSION}

During the development of a solid-phase (heterogeneous) enzyme-linked riboflavin assay with immobilized RBP [5], it was observed that even highly substituted glucose-6-phosphate dehydrogenase (G6PDH)/riboflavin conjugates with degrees of conjugation up to 26.7 could not be inhibited to a significant degree by excess of soluble RBP (i.e., $21 \%$ inhibition). This was somewhat surprising because previously it was shown that $\mathrm{G} 6 \mathrm{PDH} /$ vitamin $\mathrm{B}_{12}$, $\mathrm{G} 6 \mathrm{PDH} /$ folate, and G6PDH/biotin conjugates could be inhibited to a much greater extent by corresponding natural binders [9-11]. While low homogeneous inhibition of conjugates is actually preferred for the heterogeneous arrangements, weakly inhibited riboflavin/enzyme conjugates are not suitable for the development of a sensitive homogeneous assay system.

In subsequent work, it was found that malate dehydrogenase, when covalently linked to the 3-carboxymethylriboflavin derivative in the same manner used to prepare earlier G6PDH/riboflavin conjugates, could be inhibited up to $71 \%$ in the presence of excess of RBP. Consequently, MDH was chosen as a labeling enzyme for the development of the new homogeneous riboflavin assay. Malate dehydrogenase has been used previously in homogeneous enzymatic immunoassays for morphine [12], thyroxine [13,14], and tetrahydrocannabinol [15]. This highly stable enzyme is readily detectable at levels approaching $10^{-11} \mathrm{M}$ during a $1-\mathrm{min}$ measurement and is available in high purity.

$N(3)$-carboxymethylriboflavin was attached to the enzyme through its free carboxyl group to prepare all $\mathrm{MDH} /$ riboflavin conjugates used in this study. Numerous MDH/3-carboxymethylriboflavin conjugates were synthesized by using different initial ligand/enzyme ratios. The conjugation reaction was done without protecting the active site of the enzyme because, as suggested by Rowley et al. [12], conjugation of this enzyme in the presence of substrates could yield conjugates which cannot be inhibited. Table 1 summarizes the characteristics of the resulting conjugates. Attempts to prepare highly substituted conjugates (e.g., 250:1 or 500:1 initial riboflavin/enzyme ratios) led to insoluble products. With increasing substitution, the residual enzyme activity at first dropped off rapidly and then gradually leveled off (Table 1). However, the percent inhibition by excess of RBP did not increase proportionally with the degree of conjugation (Table 1 ). Indeed, a maximum value of $71.4 \%$ inhi- 

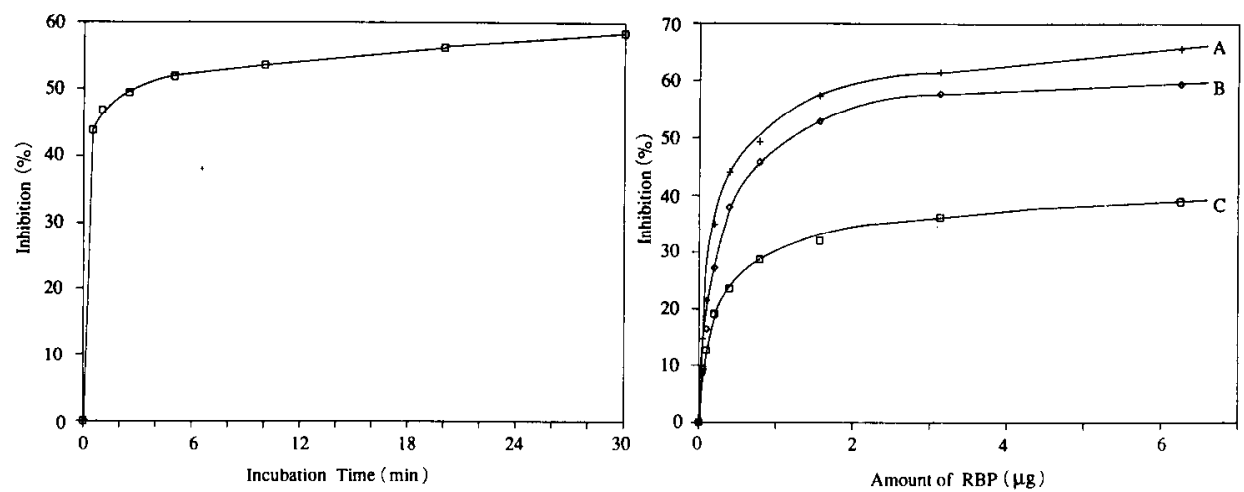

Fig. 1. Rate of association between malate dehydrogenase/riboflavin conjugate $\left(7.1 \times 10^{-9} \mathrm{M}\right.$ conj14) and RBP (15.6 $\left.\mu \mathrm{g} \mathrm{ml}^{-1}\right)$. Data points are means of quintuple measurements.

Fig. 2. Binding-protein dilution curves obtained by incubating varying amounts of RBP with the same concentration $\left(7.1 \times 10^{-9} \mathrm{M}\right)$ of three different conjugates: (A) conj-14; (B) conj-17; (C) conj-12. The $x$-axis refers to amount of RBP in the assay tubes. Means of duplicate measurements are plotted.

bition was achieved with 5.2 riboflavin residues per enzyme molecule. Inhibition induced by RBP then decreases with further riboflavin substitution.

Prior to evaluating the analytical utility of the conjugates, the kinetics of the association between the enzyme/riboflavin conjugates and RBP was studied in an effort to determine an optimal incubation time for the assay. An extremely fast association (see Fig. 1) was observed. This was expected based on the known association rate constants, on the order of $10^{7}-10^{8} \mathrm{M}^{-1} \mathrm{~s}^{-1}$, for RBP toward flavin analogs [16]. As shown in Fig. 1, >90\% of the maximum inhibition was achieved within 5 min of incubation. However, in all subsequent studies, an incubation period of $10-15$ min was used to gain a nearly maximum change in signal for the method.

A binding-protein dilution curve can be used to determine the reagent concentrations (both conjugate and RBP) required in an assay tube to obtain a desired signal change (enzyme activity and/or \% inhibition). It can also be utilized to determine the optimum concentration of binder to be used in homogeneous enzyme-linked competitive binding assays. For example, Kabakoff and Greenwood [17] suggested that the amount of binder that corresponds to $85 \%$ of the maximum homogeneous inhibition will result in a dose/response curve with optimized detection capabilities. Thus, for these purposes, three binding-protein dilution curves (Fig. 2) were constructed by using the same molar concentration of three different conjugates (conj-12, conj-14, and conj17). Surprisingly, despite the differing degrees of substitution, the maximum inhibition for each conjugate was reached at approximately the same concentration of binder. This suggests that the ratio of riboflavin residues attached 

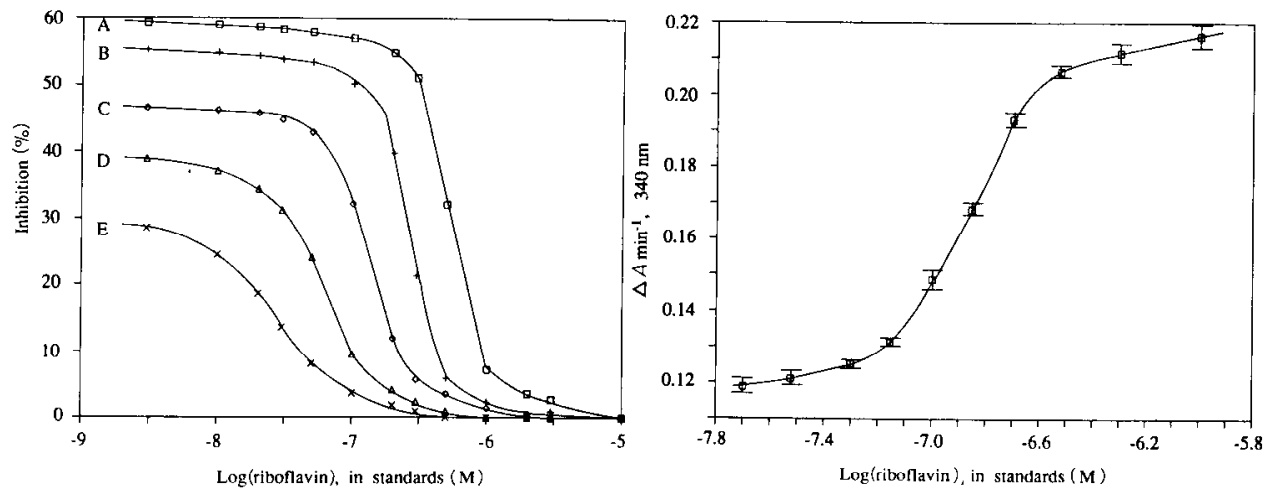

Fig. 3. The effect of various RBP concentrations on the dose/response curve for riboflavin. The concentration of conj-14 was fixed at $7.1 \times 10^{-9} \mathrm{M}$. The amounts $(\mu \mathrm{g})$ of RBP in the assay tubes were: (A) 3.12 ; (B) 1.56 ; (C) 0.78 ; (D) 0.39 ; (E) 0.20 . Data points are means of duplicate measurements.

Fig. 4. Typical calibration curve for riboflavin also showing the \pm 1 standard deviation (prepared by using the same reagent concentrations as for curve $\mathrm{C}$ in Fig. 3). Quintuple measurements were used for calculating the standard deviation.

to sites associated with RBP-induced inhibition to the total riboflavin residues in each conjugate is approximately the same, regardless of the degree of substitution of the enzyme. All subsequent analytical studies were done with conj14.

Several dose/response curves (Fig. 3 ) were constructed by varying the RBP concentration with a fixed amount of conj-14. Decreasing the binder concentration shifts the dose/response curves to lower detection ranges. However, this occurred at the expense of decreasing the extent of both the steepness and the maximum percent inhibition of the dose/response curve. It was previously reported that extremely steep curves (curves A-D) can occur when the binder shows a higher association constant toward the free analyte than the enzymelabeled analyte [18]. Indeed, the association constant of RBP toward 3-carboxymethylriboflavin $\left(7.1 \times 10^{7} \mathrm{M}^{-1}\right)$ [19], used to prepare the conjugates in this study, is a decade lower than the association constant of riboflavin $\left(7.8 \times 10^{8}\right.$ $\left.\mathrm{M}^{-1}[16]\right)$ and might be further reduced upon attachment to a bulky enzyme.

In order to evaluate the precision of the proposed method, the reagent ratio which yielded curve $\mathrm{C}$ in Fig. 3 was arbitrarily chosen and a new calibration curve was prepared along with the \pm 1 standard deviation $(n=5)$ for each point (Fig. 4). An average standard deviation of $\pm 1.9 \times 10^{-3} \Delta A \mathrm{~min}^{-1}$ (range of $0.8 \times 10^{-3}-3.0 \times 10^{-3}$ ), or an average relative standard deviation of $1.2 \%$, was obtained for the entire riboflavin concentration range tested. The relative precision in terms of riboflavin concentration, however, is also dependent on the steepness of a curve and will decrease dramatically in regions where the 


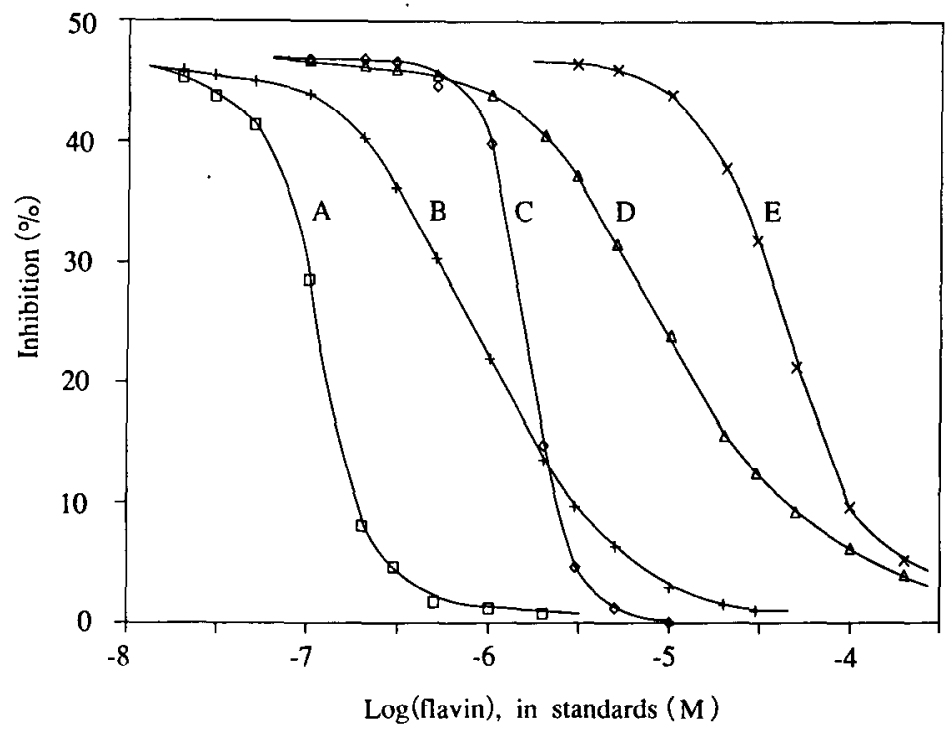

Fig. 5. Dose/response curves for riboflavin and riboflavin analogs; (A) riboflavin; (B) lumiflavin; (C) FMN; (D) lumichrome; (E) FAD. The points on the curves are means of duplicate measurements.

calibration curve flattens. Near the midpoint of the curve shown in Fig. 5, the average standard deviation $\left( \pm 1.9 \times 10^{-3} \Delta A \mathrm{~min}^{-1}\right)$ corresponds to $\pm 3.0 \%$ uncertainty in riboflavin concentrations.

The cross-reactivity of the method to several structurally related flavin analogs (lumiflavin, lumichrome, FMN, and FAD) was examined (Table 2) by using the reagent ratio which resulted in curve $\mathrm{C}$ (Fig. 3 ) for riboflavin stan-

\section{TABLE 2}

Flavin cross-reactivities of competitive binding assays

\begin{tabular}{|c|c|c|c|c|}
\hline \multirow[t]{2}{*}{ Flavin } & \multicolumn{2}{|c|}{$\begin{array}{l}\text { Cross-reactivity (enzyme-linked) } \\
(\%)\end{array}$} & \multirow{2}{*}{$\begin{array}{l}\text { Displacing } \\
\text { activityc }^{c} \\
\text { (radioassay) }\end{array}$} & \multirow{2}{*}{$\begin{array}{l}\text { Association } \\
\text { constant }^{\mathrm{d}} \\
\left(\mathrm{M}^{-1}\right)\end{array}$} \\
\hline & Homogenenus & Solid phase $^{\text {b }}$ & & \\
\hline Riboflavin & 100 & 100 & 100 & $7.8 \times 10^{8}$ \\
\hline Lumiflavin & 13.6 & 7.3 & 8.0 & $2.1 \times 10^{7}$ \\
\hline Lumichrome & 1.2 & 1.3 & & $1.1 \times 10^{7}$ \\
\hline FMN & 7.6 & 9.3 & 27.5 & $7.3 \times 10^{5}$ \\
\hline FAD & 0.3 & 0.4 & 4.0 & $<7.0 \times 10^{4}$ \\
\hline
\end{tabular}

${ }^{a}$ Determined by dividing the concentration of riboflavin at $50 \%$ of the maximum response, by the concentration of analog that yields $50 \%$ of the maximum response. ${ }^{b}$ From [5]. ${ }^{\text {From }}[20]$. ${ }^{d}$ Determined by fluorescence titration (from [16]). 

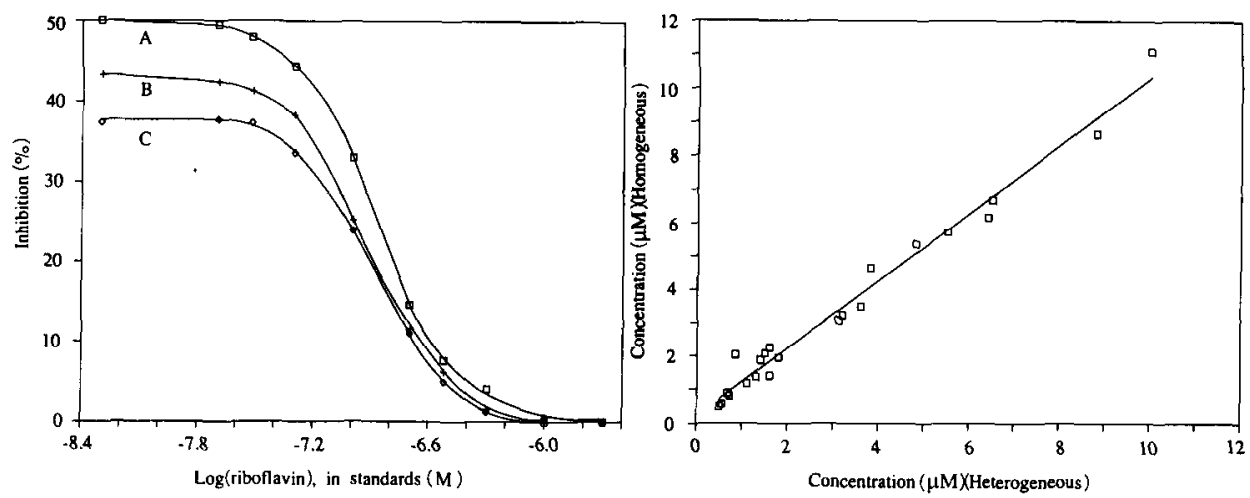

Fig. 6. Typical calibration curves obtained by using riboflavin standards prepared in a 1:10 dilution (curve C) and a 1:20 dilution (curve B) of a riboflavin-free urine pool. For comparison purposes, curve $A$ is that obtained with normal aqueous riboflavin standards. All data were obtained by using the same reagent concentrations as for curve $\mathrm{C}$ in Fig. 3. Data points are means of triplicate measurements.

Fig. 7. Correlation of the homogeneous and the heterogeneous methods for the determination of riboflavin in human urine.

dards. Figure 5 illustrates the dose/response of the homogeneous assay to these analogs. For the most part, the cross-reactivity observed was as expected based on known association constants of these analogs toward RBP (Table 2). However, a much higher cross-reactivity than expected was observed for FMN. As can be seen (Fig. 6 and Table 2), the cross-reactivity for FMN (curve C) was similar to the cross-reactivity for lumiflavin (curve B), while the association constant for FMN $\left(7.3 \times 10^{5} \mathrm{M}^{-1}\right)$ is known to be much lower than that for lumiflavin $\left(2.1 \times 10^{7} \mathrm{M}^{-1}\right)$ (association constants determined by fluorescence titration [16]). This strange observation has been reported previously, both in an earlier solid-phase riboflavin assay [5] as well as in an RBP-based radioassay for riboflavin developed by Fazekas et al. [20].

The high selectivity of the proposed method, over a wide range of other vitamins, was demonstrated by determining the riboflavin content of various commercial multivitamin preparations (Table 3 ). The new method requires only a simple dilution of the original sample. Results obtained by the present method were consistent with those determined by the fluorimetric titration method [8] and were in good agreement with the manufacturers' claims.

Preliminary studies were also undertaken to test the feasibility of using the method for the measurement of urinary riboflavin. However, it was found that both native and conjugates of MDH were significantly inhibited by components in urine. For example, the percent inhibition caused by twenty random urine samples (which were diluted 1:2 with Tris/gel/BSA (5\%) buffer), ranged from $35.8 \%$ to $49.5 \%$ with an average \pm s.d. of $43.2 \pm 5.6 \%$. Subsequent exper- 
TABLE 3

Results for determination of riboflavin in multivitamin preparations

\begin{tabular}{|c|c|c|c|c|}
\hline \multirow[t]{3}{*}{ Sample } & \multirow[t]{3}{*}{ Composition } & \multicolumn{3}{|c|}{ Riboflavin/tablet or capsule (mg) } \\
\hline & & \multirow[t]{2}{*}{ Claimed } & \multicolumn{2}{|l|}{ Found } \\
\hline & & & $\begin{array}{l}\text { Homogeneous } \\
\text { enzyme-linked } \\
\text { assay }^{\mathrm{a}}\end{array}$ & $\begin{array}{l}\text { Fluorimetric } \\
\text { method }^{\text {b }}\end{array}$ \\
\hline Capsule 1 & Vitamin B complex & 6 & $6.12 \pm 0.09$ & 6.16 \\
\hline Capsule 2 & Vitamin B complex & 50 & $52.7 \pm 2.2$ & 53.7 \\
\hline Tablet 1 & $\begin{array}{l}\text { Vitamin B complex and } \\
\text { vitamin C }\end{array}$ & 5 & $5.57 \pm 0.12$ & 5.49 \\
\hline Tablet 2 & $\begin{array}{l}\text { Vitamin B complex and } \\
\text { vitamin C }\end{array}$ & 50 & $49.7 \pm 1.0$ & 48.3 \\
\hline Tablet 3 & $\begin{array}{l}\text { Multiple vitamin (A, } \\
\mathrm{D}, \mathrm{E}, \mathrm{C} \text { and } \mathrm{B}- \\
\text { complex ) and minerals }\end{array}$ & 25 & $20.7 \pm 0.7$ & 20.8 \\
\hline
\end{tabular}

a Reported as a mean of ten determinations \pm standard deviation. ${ }^{b}$ Reported as a mean of two determinations by the method of Tillotson and Bashor [8].

iments revealed that more diluted urine causes less inhibition (i.e., $11.6 \pm 1.8 \%$ with $1: 10$ dilution and $6.8 \pm 1.2 \%$ with $1: 20$ dilution using the same twenty urine samples ). As can be seen, variations in percent inhibition between urine samples were greatly reduced by such dilutions. Thus, at least 1:10 diluted urine samples were used for all determinations. Further to improve the accuracy of the measurements in urine, the standards were prepared from a riboflavin-free urine pool. Figure 6 shows the calibration curves obtained by using a 1:10 (curve $C$ ) and 1:20 (curve $B$ ) diluted urine pool, respectively, along with the normal calibration curve A (non-urine based). By using the calibration curves prepared with urine-based standards, the riboflavin content of 22 random urine samples was determined. The results obtained (average value $=1280 \mathrm{ng} \mathrm{ml}^{-1}$; range $=184-4171 \mathrm{ng} \mathrm{ml}^{-1}$ ) coincided well with the normal ranges reported by others $[8,20]$. The same urine samples were analyzed by the earlier heterogeneous assay protocol [5] and the data obtained by two methods (homogeneous and heterogeneous) correlated quite well (Fig. 7) (correlation coefficient $=0.990$; slope $=1.01$ ). While the urine-based calibration method proposed above appears to be reliable, it should be realized that the approach increases the overall detection limits of the homogeneous assay (10-fold for the urinary riboflavin determination). However, this is not a significant problem given the normal ranges of riboflavin in urine and the absolute detection capabilities of the new method. It should further be noted that the problem of unknown urine components inhibiting MDH activity may be 
the reason that previous homogeneous enzymatic immunoassays based on $\mathrm{MDH}$ also use urine-based standards for calibration purposes [15].

In summary, a simple homogeneous assay for riboflavin has been devised. The proposed method is faster than the corresponding heterogeneous enzymelinked method and most other existing methods. The method can readily detect as little as $3 \mathrm{ng} \mathrm{ml}^{-1}\left(8 \mathrm{nM}\right.$ ) of riboflavin (or $30 \mathrm{ng} \mathrm{ml}^{-1}$ for urine samples) with excellent precision. In view of the potential for full automation of homogeneous assays, it is believed that the method described here will offer an attractive practical alternative for the routine measurement of riboflavin in a variety of samples.

We thank Ms. Genevieve S. Ashcom for her assistance in determining riboflavin in urine samples. This work was supported under Grant CHE-8506695 from the National Science Foundation.

\section{REFERENCES}

1 D. Monroe, Anal. Chem., 56 (1984) 920A.

2 A. Voller and D.E. Bidwell, in W.P. Collins (Ed.), Alternative Immunoassay, Wiley, New York, 1985, p. 77.

3 E.T. Maggio (Ed.), Enzyme-Immunoassay, CRC Press, Baco Raton, FL, 1980.

4 M. Oellerich, J. Clin. Chem. Clin. Biochem., 18 (1980) 197.

5 G.S. Cha and M.E. Meyerhoff, Anal. Biochem., 168 (1988) 216.

6 K.L. Cheng, in J.D. Winefordner (Ed.), Spectrochemical Methods of Analysis, Vol. 9, WileyInterscience, New York, 1971, p. 321.

7 C.J.R. Thorne and N.O. Kaplan, J. Biol. Chem., 238 (1963) 1861.

8 J.A. Tillotson and M.M. Bashor, Anal. Biochem., 107 (1980) 214.

9 C.D. Tsalta and M.E. Meyerhoff, Anal. Chem., 59 (1987) 837.

10 L.G. Bachas and M.E. Meyerhoff, Anal. Chem., 58 (1986) 956.

11 C.D. Tsalta, L.G. Bachas, S. Daunert and M.E. Meyerhoff, BioTechniques, 5 (1987) 148.

12 G.L. Rowley, K.E. Rubenstein, J. Huisjen and E.F. Ullman, J. Biol. Chem., 250 (1975) 3759.

13 E.F. Ullman, J. Blakemore, R.K. Leute, W. Eimstad and A. Jaklitsch, Clin. Chem., 21 (1975) 1011.

14 E.F. Ullman, R. Yoshida, J. Blakemore, E.T. Maggio and R.K. Leute, Biochim. Biophys. Acta, 567 (1979) 66.

15 R. Rodgers, C.P. Crowl, W.M. Eimstad, M.W. Hu, J.K. Kam, R.C. Ronald, G.L. Rowley and E.F. Ullman, Clin. Chem., 24 (1978) 95.

16 J. Bevcar, Ph.D. Dissertation, University of Michigan, 1973.

17 D.S. Kabakoff and H.M. Greenwood, in K.G.M. Alberti and C.P. Price (Eds.), Recent Advances in Clinical Biochemistry, Vol. 2, Livingston C, London, 1981, p. 1.

18 L.G. Bachas and M.E. Meyerhoff, Anal. Biochem., 156 (1986) 223.

19 J.D. Choi and D.B. McCormick, Arch. Biochem. Biophys., 204 (1980) 41.

20 A.G. Fazekas, C.E. Menendex and R.S. Rivlin, Biochem. Med., 9 (1974) 167. 